
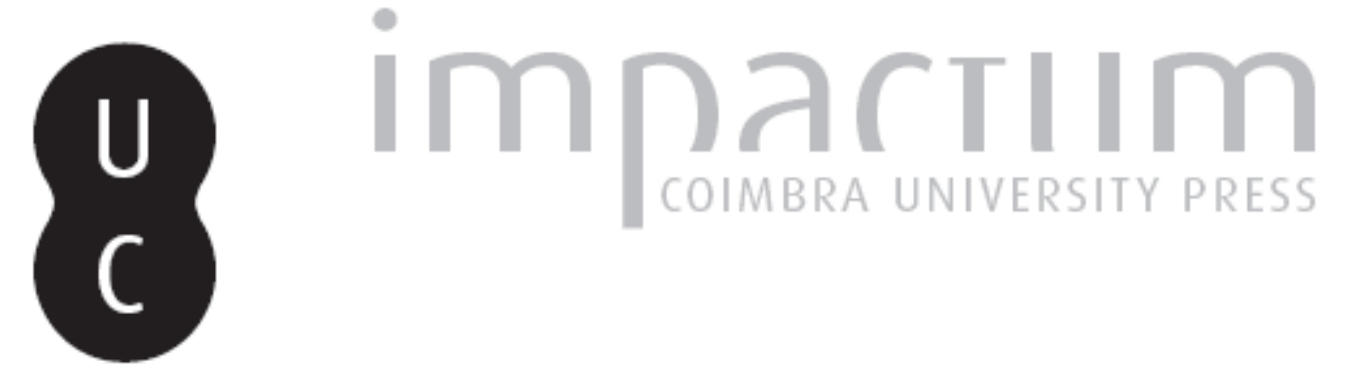

\title{
De architectis instituendis: a investigação pelo desenho depois de Bolonha
}

Autor(es): $\quad$ Fernandes, Eduardo

Publicado por: Editorial do Departamento de Arquitetura

URL persistente:

URI:http://hdl.handle.net/10316.2/37298

DOI:

DOI:http://dx.doi.org/10.14195/1647-8681_4_40

Accessed : $\quad$ 26-Apr-2023 03:40:30

A navegação consulta e descarregamento dos títulos inseridos nas Bibliotecas Digitais UC Digitalis, UC Pombalina e UC Impactum, pressupõem a aceitação plena e sem reservas dos Termos e Condições de Uso destas Bibliotecas Digitais, disponíveis em https://digitalis.uc.pt/pt-pt/termos.

Conforme exposto nos referidos Termos e Condições de Uso, o descarregamento de títulos de acesso restrito requer uma licença válida de autorização devendo o utilizador aceder ao(s) documento(s) a partir de um endereço de IP da instituição detentora da supramencionada licença.

Ao utilizador é apenas permitido o descarregamento para uso pessoal, pelo que o emprego do(s) título(s) descarregado(s) para outro fim, designadamente comercial, carece de autorização do respetivo autor ou editor da obra.

Na medida em que todas as obras da UC Digitalis se encontram protegidas pelo Código do Direito de Autor e Direitos Conexos e demais legislação aplicável, toda a cópia, parcial ou total, deste documento, nos casos em que é legalmente admitida, deverá conter ou fazer-se acompanhar por este aviso.

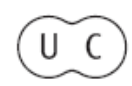




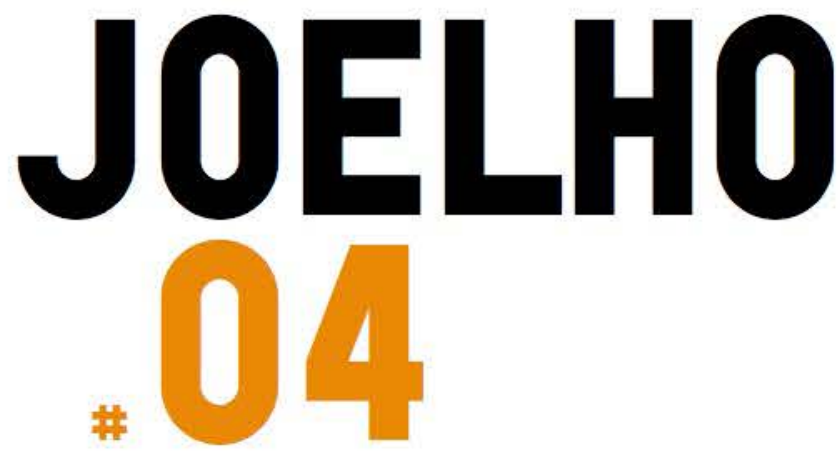

\section{ENSINAR PELO PROJETO \\ TEACHING THROUGH DESIGN}

\section{Coordenaçẫo:}

Paulo Providência

Gonçalo Canto Moniz

Alexandre Alves Costa Juan Domingo Santos Florian Beigel Philip Christou Elizabeth Hatz David Leatherbarrow Andrew Clancy Colm Moore Michael McGarry Willemijn Wilms Floet

Exposição TAPE 20Ir-12 


\section{Eduardo Fernandes De architectis instituendis: A investigação pelo desenho depois de Bolonha}

Na sua comunicação ao Simpósio Internacional La Formació de L'Arquitecte (Barcelona, Abril de 2005), Mark Wigley defendia que a profissão de arquiteto, tal como tem sido tradicionalmente encarada desde a renascença, está em vias de extinção (se não estiver já extinta) e que, para a sua sobrevivência, é necessário recordar que o arquiteto não pode apenas criar edifícios, tem de ser alguém que cria ideias sobre edifícios e edifícios que são ideias (Wigley, 2005).

Esta definição tradicional de arquiteto tem as suas raízes no séc. I a. C.: no primeiro capítulo do seu tratado (De Architectura Libri Decem) Vitrúvio fala-nos sobre a formação dos arquitetos (de Architectis Instituendis), afirmando que é necessário que sejam peritos em desenho, eruditos em geometria, doutos em história, atentos à filosofia e conhecedores de música, medicina, direito e astrologia. Mas adverte também que o arquiteto, para que possa reter na memória conhecimentos sobre um tão grande número de disciplinas, deve perceber que todas elas se relacionam e comunicam entre si, não devendo procurar ser particularmente versado em determinadas ciências, embora não deva ser ignorante de nenhuma (Vitrúvio, 2006).

Esta noção implica que o arquiteto dever ser um "especialista generalista", um técnico que sabe um pouco de tudo mas não é especialista em nada, excepto no exercício do projecto (isto é, em Investigação pelo Desenho). Este é um princípio basilar no entendimento do ensino da Arquitetura da chamada "Escola do Porto", que era apresentado a sucessivas gerações de alunos do primeiro ano da Faculdade de Arquitetura da Universidade do Porto (FAUP) por

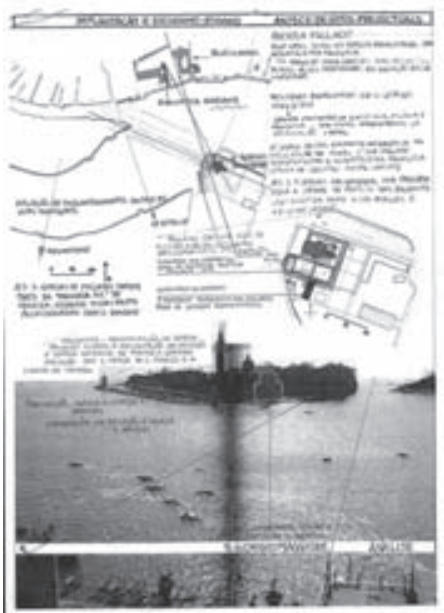

1. Análise da Igreja de San Giorgio Maggiore em Veneza (Palladio), trabalho de Maria Chicau, HAM, FAUP, 2000-01. 
Fernando Távora, na primeira aula da sua cadeira de Teoria Geral da Organização do Espaço, que apresentava a dupla responsabilidade de ser a aula de apresentação da disciplina e a primeira aula teórica do curso (Fernandes, 2011, p.643).

É claro que esta conceção vitruviana da formação de um arquiteto evoluiu, desde o século I a. C. até aos nossos dias, tornando-se muito mais abrangente ao longo do século xx: hoje, um arquiteto generalista continua a ter de saber dominar a teoria e prática do projecto e da construção, continua a precisar de saber desenhar (mas agora tem também de saber desenhar com o computador), continua a precisar de ter conhecimentos básicos de estabilidade e estruturas, térmica, acústica, história, geometria, filosofia e direito, mas tem ainda de saber alguma coisa de informática, fotografia, antropologia, sociologia, economia, ecologia e relações públicas. E continua a precisar de saber ler e escrever... o que, infelizmente, não é necessariamente um dado adquirido, num estudante universitário. Mas quanto mais complexo se torna o conjunto de saberes necessários à formação do arquiteto, mais sentido tem esta conceção abrangente e não especializada da sua formação. É nesta capacidade de cruzar conhecimentos relacionados com diferentes áreas disciplinares que reside a singularidade da educação do arquiteto, a sua habilidade para desenvolver Investigação pelo Desenho, que lhe permite criar ideias sobre edifícios e edifícios que são ideias.

Nos últimos trinta anos, no entanto, decorreu um conjunto de mudanças que são transversais a toda a sociedade e que justificam a consideração do arquiteto como uma espécie em vias de extinção.

Estamos numa era onde o tempo já não é um elemento de inteligibilidade, onde uma quotidiana overdose de informação mostra uma multiplicidade de eventos e aumenta a velocidade da história, onde os novos paradigmas levam a processos de excesso e aceleração do tempo, do espaço e do ego (Augé, 1995).

Esta aceleração e este excesso estão relacionados com processos de fusão entre realidade e representação, que levam a uma crescente digitalização da nossa envolvente física: vivemos num mundo em que existe cada vez mais informação e cada vez menos sentido, uma era de simulação em que muitas das formas actuais de actividade tendem para a publicidade, e na sua maior parte esgotam-se aí (Baudrillard,1981, p.113). Cada vez mais, a nossa vida decorre em cenários a que poderíamos chamar Generic cities (Koolhaas, 1995), Junk-spaces (Koolhaas, 2004) ou Não-lugares, espaços que não podem definir-se como identitários, relacionais ou históricos (Augé, 1995, p.83). Neste contexto, emerge facilmente a condição narcisista que hoje nos caracteriza, quando vivemos fechados num mundo digital (absorvidos por longas conversas ao telemóvel, ou abstraídos de tudo o que nos rodeia em frente ao computador) enquanto imaginamos a nossa vida de sonho através de imagens de revistas, do cinema, da televisão ou da Internet (onde podemos procurar uma "second life" de várias maneiras). ${ }^{1}$ Transformamo-nos em Wallpaper* persons, indivíduos que vivem um sonho irreal, encantado, esteticamente perfeito, num processo de simulação da realidade (Leach, 2002, p.233).

A arquitetura é um bom exemplo deste fenómeno: adquiriu recentemente um grande impacto nos meios de comunicação mais

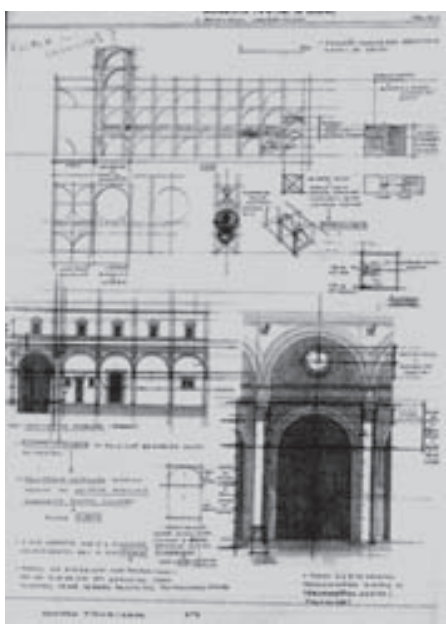

2. Análise da Igreja de San Lorenzo em Florença (Brunelleschi), trabalho de Sandra Figueiredo, HAM, FAUP, 2000-01.

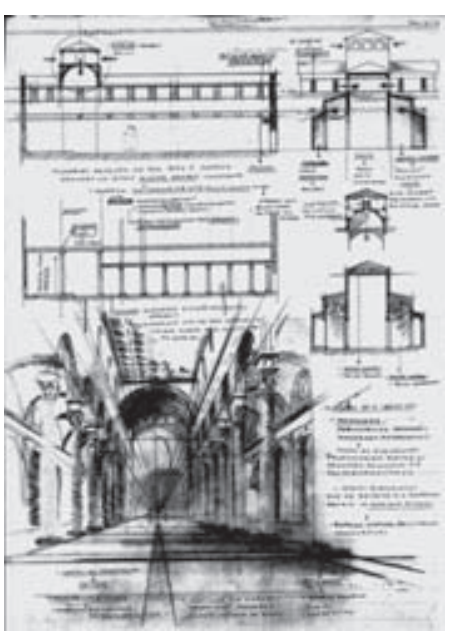

3. Análise da Igreja de San Lorenzo em Florença (Brunelleschi), trabalho de Sandra Figueiredo, HAM, FAUP, 2000-01.

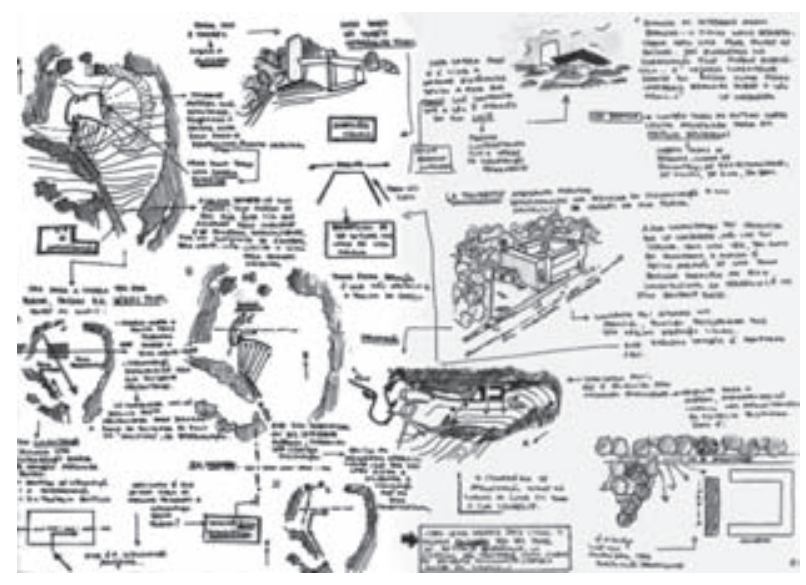

4. Análise da Capela de Notre-Dame du Haut em Ronchamp (Corbusier), trabalho de Ana Silva, Teoria I, EAUM, 2001-02. 
generalistas porque as imagens que os arquitetos criam despertam cada vez mais interesse. Isto leva-nos a dar cada vez mais importância à representação, correndo o risco de confundir boas imagens com boa Arquitetura. Assim, muitos jovens estudantes acreditam que é através da imagem dos projectos que se alcança a qualidade. Mas, muitas vezes, a perfeição do render esconde a falta de sentido construtivo, o mau entendimento do sítio, do programa ou do cliente; neste processo não há Investigação pelo Desenho, há apenas desenho, que representa muitas horas de trabalho (e o tempo, na actividade do arquiteto, ou do estudante de Arquitetura, não cresce nas árvores).

É com a consciência da necessidade de centrar o ensino da Arquitetura na Investigação pelo Desenho que tenho procurado desempenhar o meu papel de docente, iniciado na FAUP em 1999 como assistente de Métodos e Linguagens da Arquitectura Contemporânea (MLAC) e, no ano seguinte, de História da Arquitectura do Período Moderno (H AM). ${ }^{2}$ A partir de 2001, na Escola de Arquitectura da Universidade do Minho (EAUM), como responsável por várias unidades curriculares da área da Teoria, ${ }^{3}$ elaborei vários programas que começam com a mesma frase: a Teoria da Arquitetura pode e deve ser, simultaneamente, um campo de reflexão autónomo e um instrumento de apoio ao projecto.

É na tentativa de concretizar esta ideia que a generalidade dos meus exercícios práticos é pensada, solicitando ao aluno uma relação muito direta entre texto e imagem, onde o primeiro não é independente da segunda e esta nunca deve ser apenas uma mera ilustração daquele.

Sempre acreditei (mesmo quando ainda era estudante) que não devemos deixar apenas para as cadeiras de Projeto a responsabilidade de sintetizar o conhecimento que os discentes adquirem nas diferentes disciplinas que frequentam. A experiência de ensino de unidades curriculares da área da Teoria e da História em cursos de Arquitetura demonstrou-me que os alunos podem articular a abordagem de diferentes questões (a relação de um edifício com o seu contexto físico e cultural, a geometria, a escala, a composição, o significado, a funcionalidade, a tectónica, etc...) quando estudam as ideias e as obras de arquitetos de referência.

Os trabalhos realizados pelos meus alunos de MLAC e HAM, na FAUP (fig.1, 2 e 3), constituíram um primeiro campo laboratorial onde se tornaram evidentes as possibilidades do uso da imagem como meio de comunicação em trabalhos teóricos. No processo de estudo de uma obra de referência da História da Arquitetura (clássica ou contemporânea), um aluno pode fazer uma síntese do que aprendeu apresentando imagens (desenhos, fotos ou diagramas) que apoiem as suas ideias e as expliquem visualmente, em vez de escrever um paper tradicional, mais ou menos ilustrado.

Foi gratificante perceber que os alunos abordavam este tipo de trabalho com muito entusiasmado; não apenas assimilavam melhor o que liam nos livros, mas também pareciam ser capazes de compreender a forma como esses conteúdos aprendidos podiam ser úteis nos seus próprios exercícios de projeto. Este tipo de trabalho faz com que os alunos façam Investigação pelo Desenho numa ordem inversa à do seu trabalho habitual (no projecto): começando pela

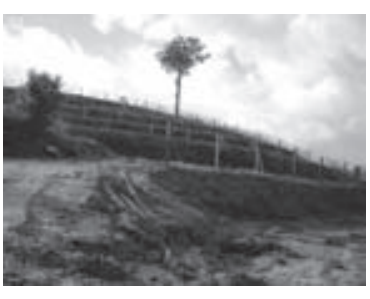

5. Terreno proposto para o exercício de Projecto III, MIARQ UM, 2008-09 (fotografia de Eduardo Fernandes).

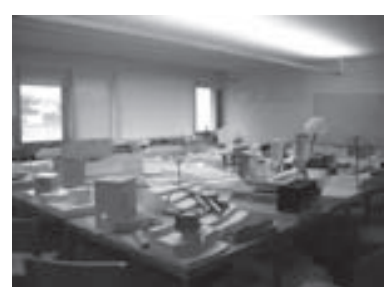

6. Várias maquetas de "casas de férias do Sr. Valery", exercício de Projecto III, MIARQ UM, 2008-09 (fotografia de Eduardo Fernandes) análise dos desenhos finais da obra que estão a estudar, procuram compreender as ideias que estão por trás das opções do autor.

É claro que, como nos exercícios de Projeto, este tipo de trabalho necessita de um tempo prático, onde possa ser supervisionado por um professor numa base semanal. No primeiro plano de estudos do Curso de Arquitetura da EAUM (que tinha como modelo o curriculum da FAUP) essas condições existiam: as cadeiras de Teoria tinham 2 horas teóricas e 2 práticas, desdobráveis em dois turnos, num total de quatro horas de carga horária semanal para o aluno que representavam seis horas para o docente. Os trabalhos propostos nas cadeiras de Teoria da Arquitetura I e II beneficiavam desta supervisão direta e mostravam o mesmo tipo de resultados (fig.4).

Foi na defesa da manutenção destas condições, tentando em vão alertar para a necessidade de manutenção dos tempos práticos da Teoria, que participei na reformulação do curso de Arquitetura da Universidade do Minho, despoletada pelo chamado "processo de Bolonha".

Pretendia-se uma aproximação a um modelo teórico uniformizador, com cursos de cinco anos (organizados semestralmente), mestrado integrado e uma carga horária de cerca de 20 horas semanais. Face a esta necessidade de comprimir o plano de estudo, tentou-se manter o leque de disciplinas existente no curriculum do primeiro ciclo, diminuindo a sua carga horária: se o Projeto passou de 12 para 10 horas (desdobrando-se em cadeiras semestrais), noutras unidades curriculares a carga horária foi drasticamente diminuída. As cadeiras de Teoria foram condenadas a tornarem-se "disciplinas de auditório", com cargas horárias mínimas ( 2 horas por semana) e um único professor para um número excessivo de alunos (cerca de 60 por ano), sem possibilidade de acompanhar convenientemente trabalhos práticos. Isto também teve consequências para o Projeto, que deixou de poder contar com o apoio da investigação prática que anteriormente se podia desenvolver na Teoria em apoio aos seus trabalhos.

Face a estas condicionantes, foi necessário procurar alternativas para obter o mesmo tipo de aprendizagem com outro tipo de exercícios. Vou apresentar aqui, como exemplo, duas experiências complementares desenvolvidas em cadeiras com a minha regência.

Em 2008 fui responsável pela Unidade Curricular de Projeto III, do segundo ano do Mestrado Integrado em Arquitetura da Universidade do Minho (MIARQ UM); com a colaboração dos meus colegas Francisco Ferreira e Joana Ribeiro, criei um exercício prático que procurava simular a relação entre arquiteto e cliente: para um dado terreno, os alunos deviam propor uma casa para o personagem Sr. Valery, a partir da leitura do livro com o mesmo nome de Gonçalo M. Tavares.

Neste livro, o Sr. Valery (um estranho personagem, inspirado no filósofo Paul Valery) explica as suas ideias para a casa de férias ideal: uma casa com apenas uma parede ou uma casa com quatro portas unidas (Tavares, 2002, p.27-28).

Confrontados com este personagem peculiar, cheio de idiossincrasias (que estavam patentes nos outros capítulos do livro), ${ }^{4}$ os alunos deviam tentar projetar uma casa de férias que respondesse às necessidades deste cliente, que devia ser bem integrada no local (uma

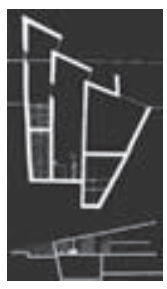

7. Comparação gráfica do corte de duas "casas de férias do Sr. Valery", Helder Castro e Marta Machado, exercício de Teoria III, MIARQ UM, 2009-10. 
colina coroada por um eucalipto de grande porte, nos limites da cidade de Guimarães) e devia funcionar como uma casa (quase) normal (fig.5). A intenção era confrontar o aluno com um cliente difícil, mas também transmitir aos discentes que é possível relacionar a área de arquitetura com a literatura e a filosofia; procurava-se assim atenuar os efeitos da diminuição do apoio da teoria ao projecto, depois de Bolonha.

Os resultados foram muito interessantes, pois mostraram abordagens invulgares para um programa que é muito comum; os alunos, inicialmente perplexos com o desafio apresentado, mostraram depois grande entusiasmo na resposta, propondo soluções com relações entre forma, função e sítio pouco usuais para este tipo de programa (fig.6).

No ano seguinte encontrei o mesmo grupo de alunos na cadeira de Teoria III (de que fui responsável), uma "cadeira de auditório" do pós-Bolonha (no terceiro ano do MIARQ UM), com muito pouco tempo para a interacção entre professor e discentes: duas horas por semanas e 60 alunos.

Acreditando que, numa cadeira de teoria, o aluno deve ser avaliado pela sua capacidade de pensar (e deve ter a oportunidade de demonstrar essa capacidade em trabalhos práticos), pedi aos alunos para fazerem um exercício de grupo, em que dois colegas realizavam uma análise crítica de um trabalho de projecto anterior (comum a ambos), comparando as diferentes respostas e apresentando as suas conclusões através de um relatório escrito (e ilustrado) e uma apresentação multimédia.
Muitos deles escolheram o exercício "Sr. Valery" (realizado no ano anterior) com resultados bastante interessantes: talvez porque este era um programa pequeno, simples de analisar, a sua comparação permitiu um discurso gráfico muito claro sobre o confronto das opções dos projetos, que por vezes apresentavam propostas muito diferentes para um mesmo programa, cliente e sítio (fig.7). Apesar das limitações de tempo, que dificultaram muito o apoio adequado aos alunos, a experiência foi positiva; permitiu compreender que este tipo de exercício, apoiado por um trabalho de projeto já realizado, possibilitava a manutenção da prática da Investigação pelo Desenho em cadeiras teóricas, depois de Bolonha.

Como é evidente, este é apenas um entre muitos caminhos possíveis; com a sucinta apresentação desta experiência pessoal não se pretendeu mais do que salientar a necessidade de continuar a luta pela sobrevivência da ideia Vitruviana do ensino da arquitetura, transmitindo aos estudantes que o arquiteto é alguém que cria ideias sobre edifícios e edifícios que são ideias (Wigley, 2005). Neste contexto, o que parece ser mais importante salientar é que esta mensagem só pode ser transmitida com eficácia se existir uma boa relação entre a Teoria e o Projeto: é na vitalidade de uma "escola-ateliê" adaptada à sociedade de informação, informada por uma renovada construção teórica (que promova a Investigação pelo Desenho), que pode residir a possibilidade dos nossos paradigmas de ensino da arquitetura sobreviverem às novas circunstâncias do mundo atual.

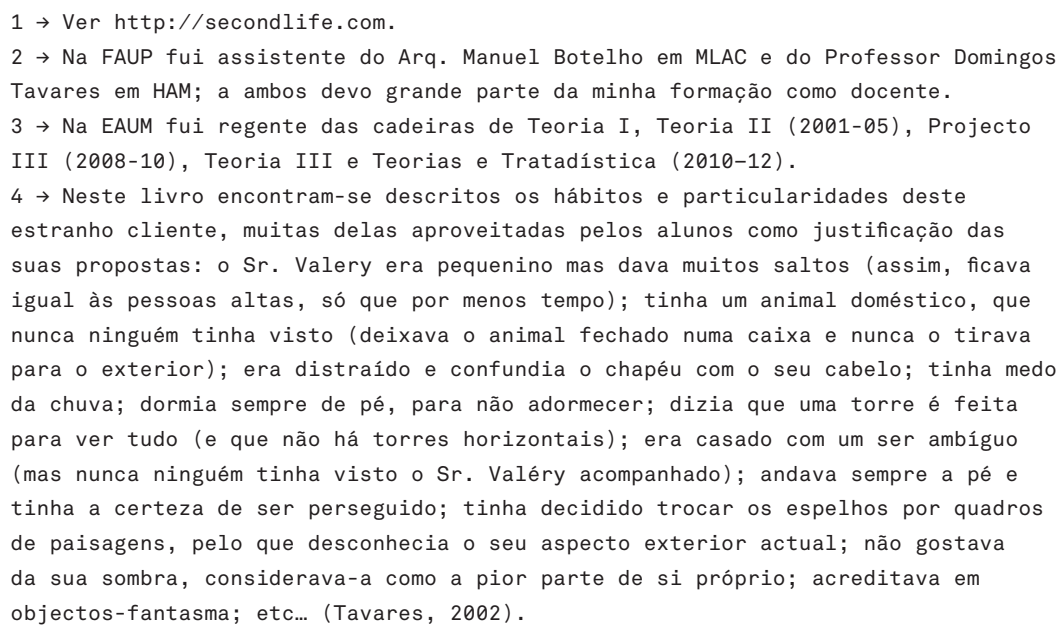

\section{Bibliographical References}

Augé, M. (1992). Non-Lieux. Paris: Éditions du Seuil. Baudrillard, J. (1981). Simulacres et simulation. Paris: Galilée.

Fernandes, E. (2011). A Escolha do Porto: contributos para a actualização de uma ideia de Escola. Dissertação de Doutoramento em Arquitectura. Guimarães: Escola de Arquitectura da Universidade do Minho (acessivel em https://repositorium.sdum. uminho.pt).

Koolhaas, R. (1995). Generic cities. In Koolhaas, R., Mau, B. (1995). S, M, L, XL. New York: Monacelli Press.
Koolhaas, R. (2004). Junk-spaces. In Koolhaas, R., /AMO/OMA/\&\&\& (2004). Content. Köln: Taschen.

Leach, N. (2002). Wallpaper* person. Notes on the behaviour of a new species. In Rattenbury, K. (Ed.), This is not architecture. New York: Routledge.

Tavares, G. (2002). O Senhor Valéry. Lisboa: Caminho.
Wigley, M. (2005). Global processes versus local singularities in architectural education, comunicação ao Simpósio Internacional La Formació de L'Arquitecte (Barcelona, Abril 2005) in Quaderns d'arquitectura i urbanisme. Barcelona: Collegi d'Arquitectes de Catalunya.

Vitrúvio (2006). Tratado de arquitectura (De architectura libri decem, séc. I a. C.), tradução de Justino Maciel. Lisboa: IST Press. 